\title{
NASALIDADE NA LÍNGUA POYANÁWA (PANO): UM EXERCICIO DE ANÁLISE
}

\section{Aldir Santos de Paula Universidade Federal de Alagoas}

\section{Introdução}

Trabalhos sobre nasalidade ou nasalização tem tido um papel relevante no desenvolvimento das teorias fonológicas modernas, que buscam representar e descrever a nasalidade nos termos da teoria autosegmental. Este trabalho tem por objetivo analisar o processo de nasalização da língua Poyanáwa' e será dividido em duas partes. $\mathrm{Na}$ primeira parte, apresentaremos os principais pontos do trabalho de Piggott (1992) que trata do processo de nasalidade, que fundamentará a análise apresentada na segunda parte.

\section{Proposta de Piggot}

Em seu artigo Variability in feature dependency: the case of nasality, Piggott (1992) postula dos sistemas de funcionamento da nasalidade nas línguas do mundo. Os padrões de harmonia nasal diferem entre si pelos segmentos que são transparentes, opacos ou alvos. Esta teoria assume que os traços fonológicos são organizados dentro de um conjunto hierarquicamente organizados de nós e que os mesmos são separados por camadas auto-segmentais, de acordo com Clements (1985) e Sagey (1986).

Segundo o autor, há duas maneiras de organizar o traço [nasal] no sistema fonológico. Em um dois padrões, há um conjunto de consoantes que bloqueia o processo de harmonia nasal, estando

A língua Poyanáwa, tipologicamente classificada como da família Pano, é falada por aproximadamente cinco falantes. O grupo habita as margens do rio Môa, município de Mâncio Lima, Estado do Acre e possui uma população em torno de 380 pessoas. A fonologia da língua foi descrita, em termos segmentais, por Paula (1992). A lingua possui acentuação predizível na última sílaba, sendo do tipo SOV (Sujeito / Objeto / Verbo) e possui um sistema de marcação de caso do tipo ergativo-absolutivo. 
incluídas as obstruintes não-continuantes. As línguas em que os segmentos obstruintes bloqueiam o processo de harmonização nasal têm o traço [nasal] organizado como dependente do nó do Palato Mole. A nasalização é produzida, de acordo com Piggott, pelo espalhamento do nódulo do Palato Mole e é bloqueada pelos segmentos que têm a especificação para o mesmo. Os segmentos são assim especificados para o Palato Mole (PM), de acordo com Piggot:

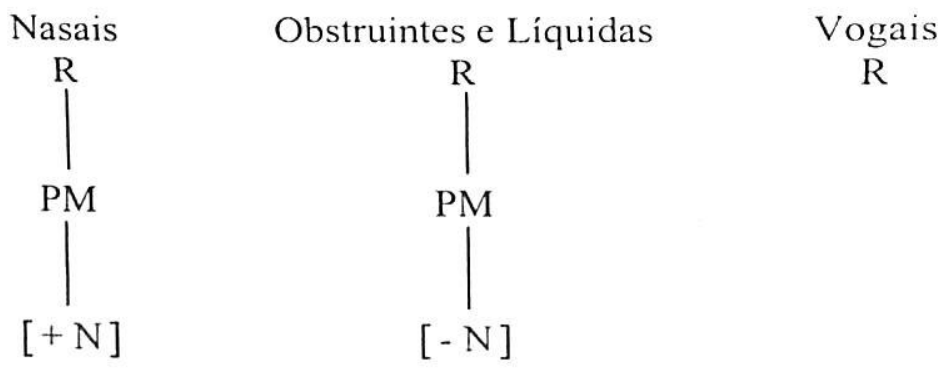

No segundo tipo de harmonia nasal, todas as obstruintes são transparentes e todas as sonorantes são alvos e não há segmento opaco. Este processo é encontrado nas línguas em que o traço [nasal] é dependente do nódulo Vozeamento Espontâneo, somente as sonorantes têm especificação para este nó. Por isso, a nasalização é espalhada de uma sonorante para outra no domínio do processo.

Esquematicamente, estes dois tipos de processos podem ser assim apresentados:

\begin{tabular}{|l|l|l|l|}
\cline { 2 - 4 } \multicolumn{1}{c|}{} & $\begin{array}{l}\text { Segmentos } \\
\text { transparentes }\end{array}$ & $\begin{array}{l}\text { Segmentos } \\
\text { opacos }\end{array}$ & $\begin{array}{l}\text { Segmentos } \\
\text { alvos }\end{array}$ \\
\hline Tipo I & -- & obstruintes, líquidas & $\begin{array}{l}\text { vogais, semivogais, } \\
\text { glides laríngeos, } \\
\text { líquidas e fricativas }\end{array}$ \\
\hline Tipo II & $\begin{array}{l}\text { obstruintes, } \\
\text { líquidas }\end{array}$ & -- & sonorantes \\
\hline
\end{tabular}

\section{A nasalidade em Poyanáwa}

A língua Poyanáwa apresenta os seguintes fonemas consonantais / p t k $\beta$ s $\int \mathrm{h}$ ts t $\mathrm{r} \mathrm{m} \mathrm{n} / \mathrm{e}$ vocálicos /

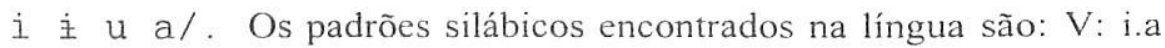
'piolho', a 'ele(a) ; CV: di 'mato', ta.ka 'figado' ; VC: uh.ka 'cabeça', 
is . ba.ia 'careca'; CVĆ: pi.a.tis 'sobrinha', pa.nan ' açaí '. Quanto à estrutura interna dos tipos silábicos, qualquer dos fonemas vocálicos da lingua pode ocupar a posição de Núcleo. Todos os segmentos consonantais podem ocupar a posição de Onset, enquanto que apenas os segmentos /h/ / s/ / / / / $/$ podem ocupar a posição de Coda. Todos os padrões ocorrem em posição tônica e pré-tônica.

Do ponto de vista fonológico, não há vogais nasais em Poyanáwa. Isto pode ser confirmado através do seguinte processo: é freqüiente ocorrer a realização da oclusiva glotal surda [ $?$ ], em nível fonético, sucedendo vogais orais, o mesmo não acontece quando existe a presença de uma vogal nasalizada.
1. [zh土?]
'semente'
2. [za?]
'eu'
3. [bipa?]
'seu pai'

Podemos supor, então, que a não-ocorrência da oclusiva glotal, após vogal nasalizada, deve-se ao fato de que a posição de coda preenchida pelo segmento nasal não pode ser ocupada por outro segmento, como se pode observar através dos seguintes exemplos:
4. [rãnhũn]
'velho'
5. [立nãn]
'eu'
6. [bipamãn]
'seu pai ?'

Além dessa ocorrência na língua Poyanáwa, é possível postular a existência da nasalização vocálica com base em análises feitas em outras línguas Pano. (Cf. Loos, 1969; Costa, 1992).

A nasalidade vocálica é obtida pelo contato com uma consoante nasal, fonte da nasalidade, situada à direita da vogal. A nasalização ocorre independentemente da posição da consoante na palavra e sem qualquer relação, aparente, com o acento da língua, como nos exemplos a seguir:

a) nasalização por contato com a consoante nasal que se encontra em posição de coda no meio da palavra: 

7. /manku/
[mã'ku ]
'paca
8. /nanbi/
[nã'bi ]
'carne
9. / hunba/
[hū'ba ]
'seios'
10. /paßinki/
[paßi'ki] 'orelha'
11. /tankara/
[tãka'ra] 'galinha'

b) nasalização por contato com a consoante nasal que se encontra em posição de coda no final da palavra:
12. / ranhun/
[rã'hũ]
'objeto velho'
13. /mian/
, [mi'à ]
teu tua
14. /t Suran/
[t $\int u r a ̃$ ]
$r a$

c) nasalização por contato com a consoante nasal :- n ; que constitui o morfema ergativo:
15. /manhu-n/
[mã'hũ] 'rapaz + Ergativo'
16. / duku-n/
[du'kũ ] 'nosso + Ergativo'

Pelos exemplos apresentados acima, a nasalidade é proveniente da consoante seguinte que se encontra na posiçãio de Coda. Dessa forma, mesmo no caso em que a consoante nasal marca o caso ergativo ( c.15 e c.16), o processo invariavelmente acontece da mesma forma: a consoante nasal passa a sua nasalıdade para o núcleo da silaba que faz parte, possibilitando a segunnte generalização: $\mathrm{v} \rightarrow \overline{\mathrm{v}} / \mathrm{N}$.

Além do processo apresentado acima. na lingua Poyanáwa acontece o espraiamento ou propagação da nasal. liste proceseso obedece ao esquema proposto por Piggotl (1992), conforme apresentado anteriormente, para as linguas do Típo I, em que o nó do Palato Mole (SP), ao qual está ligado ao traço [ + nasal ]. se esprala através dos segmentos transparentes, vogais, semivogars, glides. ctc. c é bloqueado pelos segmentos obstruintes e liquidos. liste espraramento ocorre da direita para a esquerda e é um processo de longo alcance. uma vez que ultrapassa a sílaba fonte do processo. conforme os 
exemplos abaixo, em que $\mathrm{x}=$ tempo fonológico; $\mathrm{R}=$ raiz e $\mathrm{SP}=$ nó Palato Mole:

17.

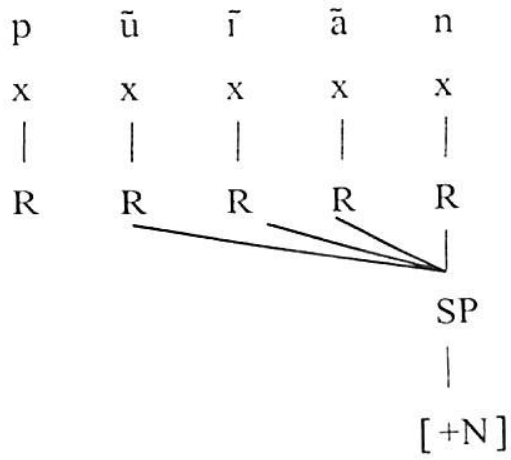

18.

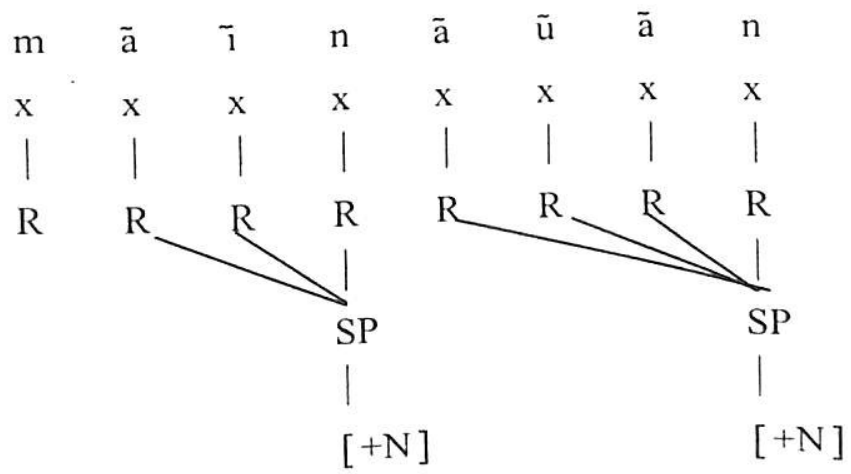

19.

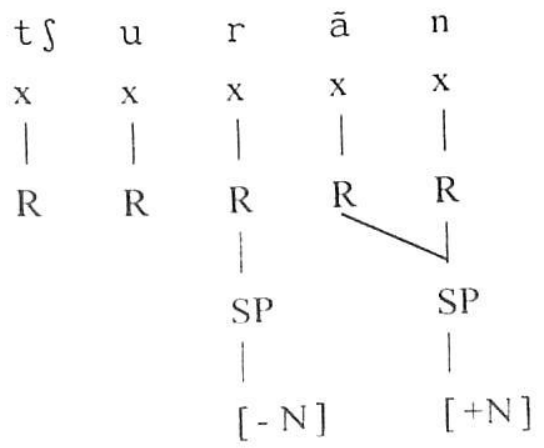


20.

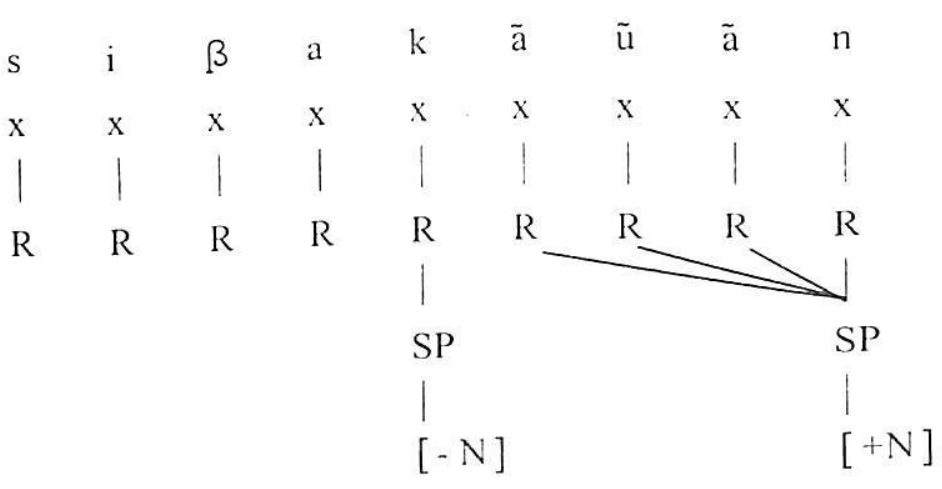

É interessante notar que, embora o espraiamento da nasalidade seja um processo freqüente na lingua Poyanáwa. como demonstrado acima, algumas ocorrências merecem uma atenção especial. exatamente por não seguirem o padrão estabelecido para a língua, embora , aparentemente, não exista nenhuma explicação para o bloqueio, tendo em vista que não ocorre a presença de segmentos obstruintes ou liquidas, como postula Piggott, o que demanda maiores estudos sobre o fenômeno:

$$
\begin{array}{ll}
\text { 21. } / \mathrm{mi} \text { 'an / } & \text { 'seu + Erg.' } \\
\text { 22. / iu'an / } & \text { 'mãe + Erg.' }
\end{array}
$$

Pode-se observar que, nos exemplos acima, a nasalização é derivada da consoante marcadora do caso ergativo e que, por isso, fica restrita ao núcleo silábico da qual ela é parte. Esta explicação sugere. então, que a fronteira morfológica pode bloquear o processo de espraiamento da nasal.

\section{CONCLUSÃO}

Ainda que de modo exploratório, tendo em vista a exigüidade dos dados, podemos sistematizar algumas idéias sobre o processo de nasalização na língua Poyanáwa: de coda ocorre sistematicamente:

- a nasalização de vogal por consoante nasal em posição

- a nasalização derivada da consóante marcadora do caso ergativo fica restrita ao núcleo silábico que precede tal consoante: 
- o processo de espraiamento da língua obedece ao esquema proposto por Piggott (1992) para as línguas do Tipo I, em que a nasalização é produzida pelo espalhamento do nódulo do Palato Mole (SP), ao qual o traço [+ nasal] está ligado, espraia-se através dos segmentos transparentes: vogais, semivogais, glides, etc. e é bloqueada pelos segmentos que têm a especificação para o mesmo, ou seja, obstruintes e líquidas .

Certamente, a nasalidade é um tema que merece atenção especial nas línguas do mundo em geral e nas línguas da família Pano, em particular, tendo em vista que a mesma apresenta-se como um fenômeno complexo que pode ter implicações nos planos fonológico e morfossintático nas línguas dessa família. A investigação sobre o tema deve continuar de modo a permitir um conhecimento mais amplo de suas implicações no quadro dos processos fonológicos da língua.

\section{REFERÊNCIAS BIBLIOGRÁFICAS}

CLEMENTS, George N. The geometry of phonological features. The phonology Yearbook 2, $225-252,1985$.

COSTA, Raquel Guimarães Romankevicius. Padrões ritmicos e marcação de caso em Marubo. Dissertação de Mestrado. Rio de Janeiro: UFRJ, 1992.

LOOS, Eugene E. The phonology os Capanahua and its grammatical basis. México: SIL, 1969.

PAula, Aldir Santos de. Poyanáwa, a lingua dos indios da aldeia Barão - aspectos fonológicos e morfológicos. Dissertação de Mestrado. Recife: UFPE, 1992.

PIGGOTT, G.L. Variability in feature dependency: the case of nasality. Netherlands, Natural Language and Linguistic Theory 10: 33-77, 1992.

SAFIR, Ken. Nasal spreading in Capanahua. Linguistic Inquiry 13: $689-694,1982$.

SAGEY, E. The representation of features and relations in antosegmental phonology: Tese de Doutorado. MIT, 1986. 